\title{
The Impact Level of Covid-19 on University Students' Mental Health in Ha Noi, Vietnam
}

\author{
Nguyen Viet Tuan Huy, Nguyen Thi Thu Hien, To Thi Thanh Hoai, \\ Nguyen Thi Tuyet, Nguyen Thi Phuong Linh \\ National Economics University, Ha Noi, Viet Nam \\ \{huynvt37, hienga42, thanhhoai1092001,nntuyet1179\}@gmail.com \\ linhnp@neu.edu.vn
}

\begin{abstract}
The coronavirus disease 2019 (COVID-19) pandemic has spread all over the world and posed a threat to the medical system of all nations. The global development of COVID-19 pandemic has resulted in direct and indirect effects on the psycho of people around the world. Numerous studies have shown that university students are experiencing particular challenges to poor mental health because of the ongoing pandemic. Recognizing the urgency of this issue, the authors conducted a study in Vietnam based on previous studies. Using a qualitative approach, this study assesses the impact of the COVID-19 pandemic on the mental health of university students in Vietnam. The authors conducted an in-depth interview with 30 students coming from 7 different universities in Hanoi. Due to the recent social distancing policy to minimize the COVID-19 cases, our interview questions were distributed, and the answers were collected during October 2021 by using an online media interview. Based on the results of the study, the authors propose a model to assess the impact of the COVID-19 pandemic on the mental health of university students in Vietnam for future research and make recommendations for governments, university administrators, and health professionals to apply this research to inform mental health practices during and after the pandemic
\end{abstract}

Index Terms-COVID-19, mental health, pandemic, university students, relationship quality, academic performance, financial stress

\section{INTRODUCTION}

$\mathrm{T}$ HE NOVEL coronavirus (COVID-19) was first detected in Wuhan, China, in late 2019 and has now quickly appeared in almost all countries [1]. COVID-19 has caused dramatic changes to the lives of billions of people across the globe and resulted in countless deaths. The ongoing global pandemic has not only exacerbated physical health but has also aggravated mental health outcomes [2].

To cope with the ongoing pandemic, most governments have instigated restrictions and enforced social distancing to minimize the consequences and protect countries from the uncontrolled spreading of coronavirus. The enforced school closures delay in-person classes and learning on online platforms on account of COVID-19, which resulted in an extensive variety of negative psychological effects on university students [3]. Because of the disruption of academic routine, poor mental health is common among university students [4]. Besides, the long-term closing of universities has led to financial losses, lack of private space, fear of infecting other family members, and lost on-campus employment... which may cause negative university students' mental health outcomes $[5,6]$.
In one study in Vietnam, about one-fourth of university students showed signs of a bad mood, and some people felt in depression [7]. Other study concluded that more than 25 percent of participants underwent mild to severe post-traumatic stress symptoms (PTSS) [8]. In general, a high rate of losing household income along with impairment in some quality of life becomes popular in Vietnam on account of the effects of the ongoing pandemic [9]. This has increased the rate of depression/anxiety. As important as that is, to date there has not been much research on the impact level of the COVID-19 pandemic on the mental health of university students in Vietnam.

This study attempts to extend existing research in the following ways. Firstly, the paper comes up with the direct and indirect influences of the ongoing pandemic on the mental health of university students. Secondly, the authors propose future research models related to these impacts.

\section{Literature Review}

\section{A. Mental Health}

Mental health is a concept that has been taken care of by many psychologists in the world because it reflects the other side of human health. Reference [10] defined: 'Mental health is a healthy state in which each person recognizes the capacity of itself, can respond to normal tension, work effectively and contribute to the community.

In detail, mental health is the foundation of happiness and productivity in every person's life. Mental health is not only the absence of mental disorders but also includes the ability to think, study, and understand one's feelings and reactions. Mental health is a state of balance, both inside the body and with the external environment. Physical, psychological, social, cultural, mental, and other related factors are all involved in creating this balance. Thus, it can be concluded that there is an inseparable connection between mental and physical health [10].

Research by UNICEF in Vietnam published in 2017 shows that about $30 \%$ of the burden of non-communicable diseases is due to mental health disorders. When facing the changes in life with multiple pressures, there is a large number of people, especially university students, who lack the necessary skills to deal with challenges. These vital skills are not naturally acquired, but they must be accumulated from life experiences. In addition, they must be formed from the knowledge base of each individual. A focus on mental 
health has the potential to generate more personal, social, and economic benefits than interventions at any time. This shows that timely psychological support and counseling will help us control our moods more proactively [11].

\section{B. The impact level of Covid-19 on university student's mental health}

\section{1) Direct influence}

Many previous studies have confirmed that the COVID19 pandemic directly affected mental health. The ongoing pandemic can worsen mental health status [12]. According to the group of authors, the COVID-19 pandemic has impacted mental health and these effects may be long-lasting. Some authors mentioned that the ongoing pandemic has a considerable psychological impact on individuals [13]. People have endured significant psychological pain during periods of a pandemic such as depression and PTSS. The rapid spread of COVID-19 has caused various effects on people's mental health [14]. Measures to prevent, treat and minimize COVID-19 as social distancing and isolation policies can adversely affect mental health, especially in high-risk people. The influence of COVID-19 on university students' mental health had been mentioned in many studies around the world [3]. The ongoing pandemic has created fear and led to a range of psychological consequences [15] typically reactions or behaviors such as anxiety, stress and substance use, anorexia, and insomnia.

COVID-19 continues to profoundly affect university students' mental health and well-being [3]. They are very worried and afraid that they will get a disease and spread coronavirus to their loved ones when they come back home. They tend to think that young people are most likely asymptomatic carriers [16].

In terms of severity, some authors suggested that most individuals had mild-moderate disorders while individuals with severe symptoms represented a minority [13]. In one study measuring the impact of COVID-19 pandemic on mental health of university students in Bangladesh, the authors concluded that about $78.1 \%$ of university students studied suffered from mental health effects due to the pandemic in Bangladesh [14]. During the pandemic, about 47\% of university students had moderate and severe anxiety.

\section{2) Indirect influence}

\section{a) Relationship Quality}

The quality of university students' relationships is one of the mediating factors affecting their mental health throughout the pandemic.

A relationship is defined as a long-term bond between two individuals [18]. A persistent pattern of interaction between at least two persons characterizes relationships [19; 20]. As a result, relationship quality includes trust, a sense of security, and fulfillment. It's also linked to a relationship's understanding, validation, and concern [21], as well as an emotional expression [21;22] and forgiveness [23].

To combat the development of COVID-19, governments have enacted harsh laws like school and company closures, curfews, and mass gathering bans, all of which have had a significant impact on teenage social contacts around the world. This has affected the quality of the interactions amongst students. COVID-19 had a direct effect on relationship quality, notably for those who had poor relationship quality [24]. Communication via the internet and social networking sites cannot replace meeting in person, even for the closest of friendships [25]. As a result, when the pandemic broke out, many scholars speculated that the stressful living conditions might increase tension in couples, which decreased relationship contentment [26].

COVID-19 can also impair the students' relationship quality since stressful situations can destabilize interactions and damage the quality of their relationships [27]. There are a variety of reasons for this, including the difficulty of group contact, the limited alternatives for sharing activities, and the lack of face-to-face interaction. Typical eye contact patterns and other forms of nonverbal interaction are interrupted with video chats. Furthermore, when the pandemic has spread and social distancing policies have been enforced, some youngsters can't access the Internet, have limited time to surf the web or use inappropriate sites. The relationship quality of these people is severely harmed.

COVID-19 has an impact on the students' relationship quality, as a result, this has an impact on their mental health. Relationship quality can affect mental health through health impacts, limitations in social activities, and communication [28; 29]. Social isolation and bad social interactions have been linked to depression [30;31] and suicide [32] in studies. The mental health of teenagers has been directly influenced by the quality of the parent-child connection [33]. Discordant relationships may be linked to a higher incidence of mood and anxiety disorders, according to a populationbased study in the United States [34]. These findings are in line with those of an Australian population-based survey, which found that better relationship quality was linked to fewer symptoms of sadness and anxiety than low relationship quality [35]. Furthermore, depression is more likely to become severe when the relationship quality is weakened. [36].

As a result, the university students' mental health is inextricably linked to their relationship quality, particularly during the COVID-19 pandemic.

b) Academic performance

COVID-19 has had an indirect impact on the mental health of students at the university through academic performance.

Academic achievement is a fundamental characteristic [37] and one of the most essential educational goals [38]. Academic performance is described as a student's evaluation based on grades or scores, as determined by professors and teachers over some time. Excellent academic achievement motivates students to do better in school and is the most essential incentive for educational institutions [39].

Many university students have been forced to switch to online learning due to the pandemic's impact. This kind of learning is an alternative to face-to-face instruction that reduces contact between students and teachers [40]. However, many students are unable to participate in online classes due to a lack of resources or tools, as well as a lack of digital equipment [41]. As a result, the COVID-19 pandemic had a moderate to severe effect on most of the participants' academic performance [42]. University students benefit from 
online education since it keeps them busy and allows them to learn on their own time. The fundamental problem of online education, however, is how to provide students with practical learning. As a result, online learning harms students' learning outcomes.

When a student's academic performance suffers, his or her mental health suffers as well. A study in Sweden found that people are more likely to experience depression in early adulthood when they have a low mean score at 16 years of age [43]. A low mean score was linked to adolescent depression hospitalization in large population research [44]. Low academic performance has an impact on later inner problems in middle age [45]. Although some studies have investigated the effects of academic success on mental health in youth and adulthood in its early stages, the majority of recent research has concentrated on depression. However, it is still true that if a student's academic performance is harmed, his mental health will be harmed as well.

\section{c) Financial Stress}

A widely accepted concept of financial stress is 'financial stress is defined as the incapacity to meet one's economic responsibilities and is affected by attitudes, beliefs, and other psychological elements' [46].

COVID-19 pandemic, along with the economic closure and social distancing policies in 2020 , has resulted in a serious economic crisis and long-term consequences: job loss, unemployment, wage cut, reduction of working hours... Some studies of America $[49 ; 50]$ showed that the unemployment rate has maintained at a relatively high level since COVID-19 pandemic broke out. American surveys also showed that nearly 90 percent of America's residents indicated that COVID-19 pandemic was bringing them stress and worries due to the loss of income or employment in their family [51].

It is indicated that undergoing financial stress throughout university (such as the inability to meet basic needs) was associated with an increase in symptoms of melancholy [47]. According to a longitudinal study in British, some undergraduate students who reported undergoing financial stress at baseline (according to the IFS) also tended to announce worry, melancholy, and cross-sectionally pressure, and nervousness after two months. Those who reported at baseline that they had thought about dropping out of school for economic reasons had higher depression scores from 6 to 8 months later [48].

In other study about university students, the authors concluded that financial stress was cross-sectionally related to poor mental health in almost all people, and went up symptoms of worry and depression [52]. It is indicated that many university students must delay their research projects and internship plans when universities must switch to online learning. This suspends their conferring of degrees and undermines their advantage and competitiveness in the labor market and occupation, which leads to stress among them [3]. Many university students have had to quit part-time or fulltime jobs due to social distancing policies that don't cover the cost of living, which in turn adds to the financial stress and mental health of students.

\section{Research Methods}

The authors used the qualitative method - in-depth interview to check the suitability of the factors in the proposed research model in the Vietnamese context. In-depth interview participants were identified as university students of many different majors at universities in Hanoi. Based on the results of in-depth interviews, the authors have correctly identified the factors that are suitable for Vietnam's conditions and the specific conditions of groups of universities in Hanoi.

The authors conducted an in-depth interview with 30 students coming from 7 different universities in Hanoi (namely: National Economics University, Hanoi University of Architecture, Hanoi University, Foreign Trade University, Hanoi University of Science and Technology, Hanoi Medical University, Hanoi National University of Education). To ensure the objectivity of this study, the authors conducted in-depth interviews with 15 male university students and 15 female university students.

Due to the social distancing policies of the government to minimize the COVID-19 cases, our interview questions were distributed and collected answers during October 2021 by using an online media interview.

The interview questions were designed by the authors with the interview content focusing on the following issues:

- COVID-19 pandemic

- University students' mental health

- Relationship quality

- Academic performance

- Financial stress

To eliminate the rigid division between "data" and "explanation", the authors use NVivo software to link parts of the research project, combining data reflection and statistics.

\section{Research Results And Proposed Research Model}

Our study conducted qualitative research, which collected information from 30 university students in Hanoi through an in-depth interview. As a result, $100 \%$ of participants said that COVID-19 had an impact on their mental health. All interviewees agreed that 'under the influence of COVID-19 pandemic, we need to pay more attention to mental health care. Research has shown that COVID-19 and its effects will continue to impact mental health. This is concerning since mental health is critical in the fight against the pandemic.

The result of the interview with 30 university students studying at universities in Ha Noi can be said to be consistent with previous studies. All interviewees agreed that relationship quality affected mental health because good relationship quality helped them not feel lonely. They felt more comfortable when they could release their feelings and vice versa. In our in-depth interview, 11 out of 30 university students thought that COVID-19 had no or little effect on their relationship because they could still communicate via the internet. Some even thought that COVID-19 was an opportunity for them to screen out unnecessary relationships. The rest said that the quality of their relationship was negatively affected by COVID-19 both in terms of friends and family. This caused them to have unresolved negative emotions and prolonged sadness, which led to stress and depression. 
The result showed that 9 out of 30 university students had no difficulty in learning online. They were even interested in learning online. The rest found online learning more difficult to absorb knowledge because of the lack of textbooks, supplementary materials, and the unstable quality of the transmission line. Besides, the lack of real-world experiences in online classes and the limited communication between lecturers and university students also made them feel online classes were not as desirable as onsite ones. 23 out of 30 interviewees indicated that their study results were negatively affected by the COVID-19 pandemic. The knowledge acquisition was limited, the forms of study and exam change, so everyone felt nervous during the study and exam period. Many university students had fallen into depression after the exams because the test results were not as good as expected.

The interview results also showed that $50 \%$ of attendees had difficulties in paying fees: rent, tuition fees, electricity and water bills, personal expenses... 15 out of 30 university students said that their household incomes have been negatively affected since the COVID-19 pandemic broke out. Because of social distancing and isolation measures, their parents had to work at home or decrease their working hours, which made household incomes reduced significantly. This was the reason why they had to reduce spending and worried about tuition fees. As a result, they felt stressed and anxious. Therefore, the COVID-19 pandemic aggravated financial stress among university students, which resulted in poor mental health outcomes.

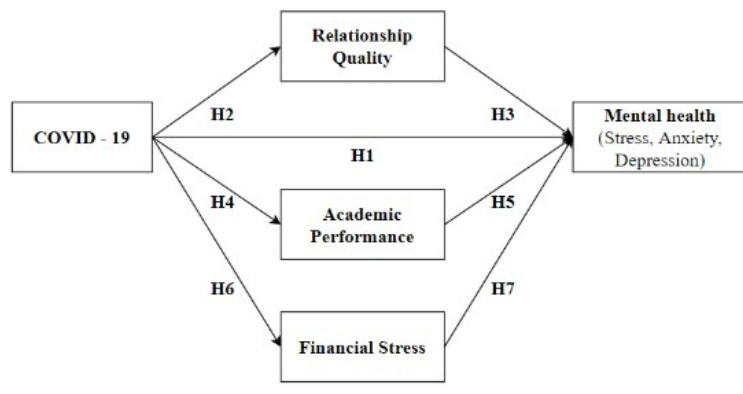

Fig. 1 Research model

For those reasons, the study of the impact of COVID-19 and its accompanying effects on mental health and finding reasonable solutions is very important and critical.

We propose the research model for future study as shown in Fig.1.

From our research model, we propose 7 research hypotheses:

1. Hypothesis 1: COVID-19 negatively affects university students' mental health

2. Hypothesis 2: COVID-19 negatively affects relationship quality

3. Hypothesis 3: Relationship quality proportionally affects university students' mental health

4. Hypothesis 4: COVID-19 negatively affects academic performance

5. Hypothesis 5: Academic performance proportionally affects university students' mental health

6. Hypothesis 6: COVID-19 proportionally affects financial stress
7. Hypothesis 7: Financial stress negatively affects university students' mental health

\section{Conclusion}

The influence of the COVID-19 pandemic on the mental health of university students was explored in this study. We researched the elements impacting the mental health of student groups to analyze the prevalence of psychological difficulties produced by COVID-19 among students and to investigate the association between mental health and the COVID-19 pandemic. The COVID-19 pandemic has had a direct impact on the mental health of university students and indirectly through several factors: relationship quality, academic success, and financial stress.

The authors used a qualitative research method - an indepth interview with 30 students in different university groups in Hanoi to confirm the direct and indirect relationship between the COVID-19 pandemic and university students' mental health in the current context of Vietnam. Due to time constraints, the research team only surveyed and interviewed a small group of students. Taking the survey only among students in the north as a representative sample of students makes the research work still incomplete.

Inheriting, supplementing, and developing from previous studies, the authors propose a research model of factors affecting university students' mental health during the COVID-19 pandemic with 3 mediating variables: relationship quality, academic performance, and financial stress respectively. The authors recommend that future researchers apply this research model to study by quantitative method to find out effective university students' mental health interventions during and after the COVID-19 pandemic.

\section{REFERENCES}

[1] Barbara Nussbaumer-Streit, Mayr V, Dobrescu AI, Chapman A, Persad E, Klerings I, et al. Quarantine alone or in combination with other public health measures to control COVID19: a rapid review. Cochrane Infectious Diseases Group, editor. Cochrane Database Syst Rev. 2020;2020:CD013574

[2] Ulrike Ravens-Sieberer, Anne Kaman, Michael Erhart, Christiane Otto, Janine Devine, et al. Quality of life and mental health in children and adolescents during the first year of the COVID-19 pandemic: Results of a two-wave nationwide population-based study. 2021.

[3] Zhai, Y., \& Du, X. (2020). Addressing collegiate mental health amid COVID-19 pandemic. Psychiatry Research, 288, 113003.

[4] Agnew, M., Poole, H., Khan, A. Fall break fallout: exploring student perceptions of the impact of an autumn break on stress. Student Success. 2019.

[5] Cao, W., Fang, Z., Hou, G., Han, M., Xu, X., Dong, J., Zheng, J., 2020. The psychological impact of the COVID-19 epidemic on college students in China. Psychiatry Res.

[6] Wang, C., Pan, R., Wan, X., Tan, Y., Xu, L., Ho, C.S., Ho, R.C., 2020. Immediate Psychological Responses and Associated Factors during the Initial Stage of the 2019 Coronavirus Disease (COVID-19) Epidemic among the General Population in China. Int. J. Environ. Res. Public Health 17, 1729.

[7] Thien Khai Tran, Hoa Dinh, Hien Nguyen, Dac-Nhuong Le, Dong-Ky Nguyen et al. The Impact of the COVID-19 Pandemic on College Students: An Online Survey. 2021.

[8] Xuan Thi Thanh Le, Anh Kim Dang, Jayson Toweh, Quang Nhat Nguyen, Huong Thi Le, Toan Thi Thanh Do, Hanh Bich Thi Phan et al. Evaluating the Psychological Impacts Related to COVID-19 of Vietnamese People Under the First Nationwide Partial Lockdown in Vietnam. 2020. 11:284.

[9] Bach Xuan Tran, Hien Thi Nguyen, Huong Thi Le, Carl A. Latkin et al. Impact of COVID-19 on Economic Well-Being and Quality of Life 
of the Vietnamese During the National Social Distancing. Front Psychol. (2020) 11:565153.

[10] WHO, (2001) The World Health Report 2001, Mental Health: New Understanding, New Hope. World Health Organization, Geneva.

[11] Hong Chau, 2019, Facing the pressures of modern society, Nhan Dan, https://nhandan.vn/chuyen-de-cuoi-tuan/oi-dien-ap-luc-cua-xa-hoihien-dai-380058/?

fbclid=IwAR33mkRyNXnb0Wp7Wyb8emdHIm5iN9XpfyNrQmm ti zjlIdaIin6a1CNu2E, accessed on October 1, 2021

[12] Moreno, C., Wykes, T., Galderisi, S., Nordentoft, M., Crossley, N Jones, N., ... \& Arango, C. (2020). How mental health care should change as a consequence of the COVID-19 pandemic. The Lancet Psychiatry.

[13] Talevi, D., Socci, V., Carai, M., Carnaghi, G., Faleri, S., Trebbi, E., .. \& Pacitti, F. (2020). Mental health outcomes of the CoViD-19 pandemic. Rivista di psichiatria, 55(3), 137-144.

[14] Kola, L. (2020). Global mental health and COVID-19. The Lancet Psychiatry, 7(8), 655-657.

[15] Liu, S., Yang, L., Zhang, C., Xiang, Y.-T., Liu, Z., Hu, S., et al. (2020). Online mental health services in China during the COVID-19 outbreak. Lancet Psychiatry 7, e17-e18.

[16] Pan, S. L., \& Zhang, S. (2020). From fighting COVID-19 pandemic to tackling sustainable development goals: An opportunity for responsible information systems research. International Journal of Information Management, 55, 102196.

[17] Patwary, M. M., Bardhan, M., Disha, A. S., Kabir, M., Hossain, M. Alam, M., ... \& Billah, S. M. (2020). The Impact of COVID-19 Pandemic on Mental Health of University Student: A Cross-Sectional Study in Bangladesh. Riad and Alam, Md. Ashraful and Haque, Md. Zahidul and Billah, Sharif Mutasim, The Impact of COVID-19 Pandemic on Mental Health of University Student: A Cross-Sectional Study in Bangladesh (June 27, 2020).

[18] Reis, H.T. (2001). Relationship experiences and emotional wellbeing. In C.D. Ryff \& B.H. Singer (Eds.), Emotion, social relationships and health (pp. 57-95). New York: Oxford University Press.

[19] Asendorpf, J.B., \& Banse, R. (2000). Psychology of relationships. Berlin: Springer.

[20] Hinde, R. (1993). On the way toward a science of social relationships. In A.E. Auhagen \& M. von Salisch (Eds.), Interpersonal relationships (pp. 7-36). Gottingen: Hogrefe.

[21] Clark, M.S., Fitness, J., \& Brissette, I. (2001). Understanding people's perceptions of relationships is crucial to understanding their emotional lives. In G. Fletcher \& M.S. Clark (Eds.), Blackwell handbook of social psychology: Interpersonal processes (pp. 253-278). London: Blackwell.

[22] Feeney, J.A. (1999). Adult attachment, emotional control, and marital satisfaction. Personal Relationships, 6, 169-185.

[23] McCullough, M.E. (2000). Forgiveness as human strength: Theory, measurement, and links to well-being. Journal of Social and Clinical Psychology, 19, 43-55

[24] Pieh C, O'Rourke T, Budimir S, Probst T (2021) Correction Relationship quality and mental health during COVID-19 lockdown. PLOS ONE 16(9): e0257118.

[25] Foulkes, L., \& Blakemore, S.-J. (2021). Individual differences in adolescent mental health during COVID-19: The importance of peer relationship quality. Neuron.

[26] Pietromonaco, P. R., \& Overall, N. C. (2021). Applying relationship science to evaluate how the COVID-19 pandemic may impact couples' relationships. American Psychologist, 76(3), 438-450

[27] Neff, L. A., Karney, B. R. (2017). Acknowledging the elephant in the room: How stressful environmental contexts shape relationship dynamics. Current Opinion in Psychology, 13, 107-110

[28] Kawachi I, Berkman LF (2001) Social ties and mental health. J Urban Health 78: 458-46.

[29] Berkman LF, Glass T (2000) Social integration, social networks, social support, and health. In: Berkman LF, Kawachi I, editors. Social Epidemiology. New York: Oxford University Press. 137-173.

[30] Chou KL, Liang K, Sareen J (2011) The association between social isolation and DSM-IV mood, anxiety, and substance use disorders: wave 2 of the national epidemiologic survey on alcohol and related conditions. J Clin Psychiatry.
[31] Schuster TL, Kessler RC, Aseltine RH (1990) Supportive Interactions, Negative Interactions, and Depressed Mood. American Journal of Community Psychology 18: 423-438.

[32] Holma KM, Melartin TK, Haukka J, Holma IA, Sokero TP, et al. (2010) Incidence and predictors of suicide attempts in DSM-IV major depressive disorder: a five-year prospective study. Am J Psychiatry 167: 801-808.

[33] Hazel NA, Oppenheimer CW, Technow JR, Young JF, Hankin BL (2014) Parent relationship quality buffers against the effect of peer stressors on depressive symptoms from middle childhood to adolescence. Dev Psychol 50:2115-2123.

[34] Whisman MA, Sheldon CT, Goering P (2000) Psychiatric disorders and dissatisfaction with social relationships: does type of relationship matter? J Abnorm Psychol 109: 803-808.

[35] Leach LS, Butterworth P, Olesen SC, Mackinnon A. Relationship quality and levels of depression and anxiety in a large populationbased survey. Soc Psychiatry Psychiatr Epidemiol. 2013; 48:417-25.

[36] Teo AR, Choi H, Valenstein M. Social relationships and depression: ten-year follow-up from a nationally representative study. PLoS ONE. 2013;8:e62396

[37] Silva, F. R. da, Guerreiro, R. de C., Andrade, H. de A., Stieler, E., Silva, A., \& de Mello, M. T. (2020). Does the compromised sleep and circadian disruption of night and shiftworkers make them highly vulnerable to 2019 coronavirus disease (COVID-19)? Chronobiology International, 1-11. doi:10.1080/07420528.2020.1756841

[38] Narad, A., \& Abdullah, B. (2016). Academic performance of senior secondary school students: Influence of parental encouragement and school environment. Rupkatha Journal on Interdisciplinary Studies in Humanities Special Issue, 3(2), 12-19.

[39] Adeyemo, D. A. (2001). Teachers' job satisfaction, job involvement, career and organizational commitments as correlates of studentacademic performance. Nigerian journal of applied psychology, 6(2), 126-135.

[40] Pragholapati A. COVID-19 impact on students. EdArXiv [Preprint]. (2020). p. 1-6.

[41] UNESCO. Universities Tackle the Impact of COVID-19 on Disadvantaged Students. (2020). Available online at: https:// en.unesco.org/news/universities-tackle-impact-covid-19disadvantaged-students (accessed May 24, 2020).

[42] Mahdy, M. A. A. (2020). The Impact of COVID-19 Pandemic on the Academic Performance of Veterinary Medical Students. Frontiers in Veterinary Science, 7

[43] Sörberg Wallin A, Koupil I, Gustafsson JE, Zammit S, Allebeck P, Falkstedt D (2019) Academic performance, externalizing disorders and depression: 26,000 adolescents followed into adulthood. Soc Psychiatry Psychiatr Epidemiol 54(8):977-986.

[44] Jonsson U, Goodman A, von Knorring AL, von Knorring L, Koupil I (2012) School performance and hospital admission due to unipolar depression: a three-generational study of social causation and social selection. Soc Psychiatry Psychiatr Epidemiol 47(10):1695-1706.

[45] Deighton J, Humphrey N, Belsky J, Boehnke J, Vostanis P, Patalay P (2018) Longitudinal pathways between mental health difficulties and academic performance during middle childhood and early adolescence. Br J Dev Psychol 36(1):110-126.

[46] Jebediah J. Northern, William H. O'Brien, Paul W. Goetz. The Development, Evaluation, and Validation of a Financial Stress Scale for Undergraduate Students. 2010.

[47] Andrews B, Wilding JM. The relation of depression and anxiety to life-stress and achievement in students. Br J Psychol 2004; 95:509-21.

[48] Thomas Richardson, Peter Elliott, Ron Roberts, Megan Jansen. A longitudinal study of financial difficulties and mental health in a national sample of British undergraduate students. 2017.

[49] Kochhar, R. Unemployment Rose Higher in Three Months of COVID19 Than It Did in Two Years of the Great Recession. 2020

[50] M. Felsenthal. COVID-19 to Plunge Global Economy into Worst Recession Since World War II. 2020.

[51] Close Nefe. Survey: Nearly 9 in 10 Say COVID-19 Crisis is Causing Financial Stress. 2020.

[52] Tayla McCloud and David Bann. Financial stress and mental health among higher education students in the UK up to 2018: rapid review of evidence. 2019 